\title{
Do patients like day case cataract surgery?
}

\author{
B Davies, A G Tyers
}

\begin{abstract}
One hundred and fifty consecutive questionnaires following day case cataract surgery showed that $87 \%$ of the patients would choose day surgery again. The questionnaires were directed at the patients' attitudes to day surgery for their cataracts. There was overwhelming acceptance of the travelling and inconvenience involved.
\end{abstract}

The visual results and postoperative complications following day case cataract surgery are not significantly different from cataract surgery in hospitalised patients. ${ }^{1-3}$

Each year more patients in Britain are having cataract surgery: the number of elderly people in the population is rising; patients are being operated upon earlier with advances in microsurgery and greater patient demand; and most patients require both eyes to be operated upon.

Day case cataract surgery has been found to be acceptable to patients in a general way, ${ }^{4}$ but few previous studies examining patients' attitudes to specific aspects of day surgery for cataracts have been published. ${ }^{\mathrm{s}}$

\section{Materials and methods}

One hundred and fifty consecutive questionnaires were collected from 146 patients (four had both eyes operated upon on separate occasions in this study). Sixty were male and 86 female; their ages ranged from 51 to 98 years, mean 73.6 years.

The protocol for day case cataract surgery has remained unchanged since it was introduced in Salisbury in 1987. The patients already listed for cataract extraction are offered day case cataract surgery as they approach the top of the waiting list. They are sent information explaining the meaning of day case cataract surgery and what would be required of them (their own transport and a relative or friend to accompany them on their various hospital visits). If they decline, it is emphasised to them that they keep their place on the waiting list in the usual way. If they accept, they are asked to return an enclosed acceptance form. It is stressed that hospital transport is not available. Patients are omitted from this option if they are insulin dependent diabetics, or on warfarin, or if they are poorly controlled hypertensives. Since all day case cataract surgery is under local anaesthesia, the very deaf, the demented, and those who do not speak English are also excluded.

The patients who accept day case surgery attend a preadmission clinic about 2 weeks prior to admission. They spend 20-30 minutes with the senior house officer, who takes the medical history, performs a general examination, eye examination, keratometry and an A scan, then gives further explanation on procedure, and confirms the date for operation once consent has been taken.

On the day of operation they are admitted on to the day ward having taken a light breakfast and their routine medication. Preoperative dilating drops are instilled. No premedication is given.

They are taken on a trolley to the main theatre suite and retrobulbar anaesthesia with facial nerve block is given in the anaesthetic room. No intravenous sedation is given. After operation the patients are taken back to the ward to be collected by their relative(s) or friend(s) 1 hour later, having had refreshments.

During the period of this study the operations were performed by the consultant, senior registrar, or registrar using a standard extracapsular technique and lens implantation.

The patients are requested to return to the clinic the following morning for the first dressing. After slit-lamp examination they are given their postoperative medication to take home. They are then all given a questionnaire to complete at home (Fig 1) and bring back at a later visit.

The patients are reviewed again on the third postoperative day and again 2 weeks later, when the questionnaires are collected. After this there is routine follow-up in the clinic in the standard way.

\section{Results}

In this study $70 \%$ of patients accepted the offer of day case cataract surgery. Analysis of the completed questionnaires showed that $93 \%$ found no problem with the journey to hospital. In $43 \%$ the journey took less than half an hour; $55 \%$ said the journey took between a half and 1 hour, and only $2 \%$ took more than 1 hour. $80 \%$ said that if they had lived twice as far from the hospital, they would still have preferred outpatient surgery.

$91 \%$ found it no problem to arrange a relative or a friend to accompany them. $13 \%$ had no discomfort whatsoever after the operation; $52 \%$ experienced a little discomfort only; $31 \%$ found it moderately painful; $4 \%$ had severe pain. $93 \%$ of patients found that paracetamol was sufficient to control the discomfort. $89 \%$ had no problems cleaning the eye at home (after the first dressing). $87 \%$ said that, if they were to have the operation again, they would prefer it as an outpatient.

There were no significant comments by the patients that added anything to the results of the questionnaires.

\section{Discussion}

The recent reports on day surgery of the Audit Commission $^{6}$ and the NHS Management Executive Value For Money Unit ${ }^{7}$ strongly support an expansion of day surgery in most surgical special- 
Name

$$
\text { Hospital No. }
$$$$
\text { Date }
$$

You have recently had your eye operation as an outpatient. Would you please help us by answering some questions? Please tick your answers.

(a) Did you find the journey difficult? 1.Yes 2 . No

(b) How long did your journey take, one way?

3. Less than $1 / 2$ hour

$4.1 / 2$ to 1 hour

5.1 to 2 hours

6.2 to 3 hours

7. More than 3 hours

(c) If you had lived twice as far from the hospital, would you still have preferred outpatient surgery?

$$
\text { 8.Yes_ 9.No___ }
$$

(d) Did you find it difficult to arrange a friend or a relative to accompany you?

$$
\text { 10. Yes. }
$$

11 . No

(e) How much discomfort did you have after your operation? 12. None_ 13.A little_ 14.Moderate_15.Severe

(f) Did you find that mild painkillers like paracetamol were enough?

$$
\text { 16.Yes_ } 17 \text {. No }
$$

(g) Did you have any problems cleaning the eye at home? 18.Yes 19. No

(h) If you had your operation again would you still prefer it as an outpatient? 20. Yes_ 21.No

(i) Do you have any other comments?

Figure 1 Questionnaire. hospital services to a catchment population of approximately 185000 . About $40 \%$ of all cataract extractions are performed as day cases though at present no designated day surgery unit exists. Although many patients travel from villages some distance away, travelling was not a problem for $93 \% ; 80 \%$ would still have chosen day surgery if they had lived twice as far away. $91 \%$ had no difficulty arranging to be accompanied. In a recently published report on day case cataract surgery in the urban area around Bristol a similar percentage $(82 \%)$ would prefer day surgery again. If those expressing no preference are included, $97 \%$ were content with day surgery.

Not being in hospital was not found to be a problem by the majority of patients. $89 \%$ had no problem cleaning the eye at home after the first dressing had been done in the clinic. Although only $13 \%$ had no postoperative discomfort whatsoever, $93 \%$ of patients found that paracetamol was adequate to control what discomfort they experienced.

This is a selected group of patients in that some patients are not offered day surgery because of medical or other reasons, and of those who are offered day surgery $30 \%$ declined. Of those $70 \%$ who requested day surgery $87 \%$ would prefer day case surgery again. The reasons given by the $13 \%$ of patients not wanting day surgery again were not specified in one-third, but the remainder gave as reasons the difficulty attending all the hospital visits, too short a recovery time before discharge, and being alone at home. Only $2 \%$ of the total number of patients objected to local anaesthesia.

More than $75 \%$ of all cataract operations done in Salisbury are under local anaesthesia, and the surgery has been found to be only slightly more stressful for the surgeon than with general anaesthesia.

The findings of this study support our overwhelming impression that day case cataract surgery is preferred by the majority of patients. Because of this level of acceptability and the good clinical outcome, demand is likely to increase. outcomes have been shown to be as good as under inpatient care. In addition, an integrated day surgery facility offers a service which can avoid cancellations to a greater degree than is possible with inpatient care. ${ }^{67}$ Patients' attitudes to day surgery have not received the same attention as the clinical outcomes, ${ }^{89}$ and the Audit Commission has recently proposed a questionnaire which could be used to study them. ${ }^{10}$

Patients who are offered day surgery in Salisbury have to arrange their own transport and escort, and they have to return to the clinic for review rather than be visited by a nurse in the immediate postoperative period. Salisbury is primarily a rural area with a resident population of about 125000 . The Health Authority provides 1 Ingram RM. Day case ophthalmic surgery. $\mathcal{F} R$ Soc Med 1984;

2 Davies PD, Limacher E, Powell K. Outpatient cataract surgery 1982-1986. Eye 1987; 1: 728-34.

3 Watts MT, Pearce JL. Day case cataract surgery Brf Ophthalmol 1988; 72: 897-9.

4 Smith S. Day care cataract surgery. The patients' perspective. 7 Ophthalmic Nurs Technol 1987; 6: 50-6.

5 Lowe KJ, Gregory DA, Jeffery RI, Easty DL. Patient perceptions and social impact. Preliminary results of the Bristol MRC study. Eye 1991; 5: 373-8.

6 Audit Commission. A short cut to better services - day surgery in England and Wales. London: HMSO, 1991.

7 NHS Management Executive Value For Money Unit. Day surgery - making it happen. London: HMSO, 1991.

8 Ingram RM, Banerjee D, Traynar MJ, Thompson RK. Day case cataract surgery. Brf Ophthalmol 1983; 67: 278-81.

9 Schanzer MC, Wilhelmus KR. Outpatient cataract surgery by ophthalmology residents in a county hospital. Ann Ophthalmol 1985; 17: 480-2. day surgery. London: HMSO, 1991.
10 Audit Commission. Measuring quality; the patients' view of 